\title{
A prática esportiva como ferramenta educacional: trabalhando valores e a resiliência
}

Simone Meyer Sanches

Kátia Rubio

Universidade de São Paulo

\section{Resumo}

A sociedade brasileira vislumbra, na atualidade, o desafio de organizar e realizar megaeventos esportivos de grande impacto social. Nesse contexto, a atividade esportiva pode ser considerada uma ferramenta eficaz de intervenção psicossocial, especialmente com crianças e jovens. A presente pesquisa teve por objetivo investigar situações e vivências de atletas de alto rendimento relacionadas ao aprendizado decorrente da inserção nesse contexto e aos valores ali preconizados. Foram realizadas entrevistas por meio do método de história de vida com quatro atletas de duas equipes de atletismo do interior do Estado de São Paulo. Os dados foram categorizados e o conteúdo foi analisado qualitativamente. Os resultados apontaram para diversas contribuições decorrentes da inserção no contexto esportivo, algumas atreladas às transformações externas, como a melhora da condição estética, financeira ou de inclusão social, e outras relacionadas aos aspectos internos e subjetivos, como o reforço e o desenvolvimento de valores de cooperação, amizade, solidariedade e a capacidade de compartilhar e de superar adversidades (resiliência). Conclui-se que a atividade esportiva, quando bem conduzida (por profissionais bem capacitados), pode beneficiar tanto o desenvolvimento global do praticante, quanto os demais ambientes nos quais ele está inserido, como a família e o grupo de iguais, ampliando as contribuições para a sociedade de modo geral.

\section{Palavras-chave}

Esporte - Educação - Valores - Resiliência.

Correspondência:

Simone Meyer Sanches

Rua Dr. Ruy Vicente de Mello, 441

13083-745 - Campinas/SP

si_sanches@hotmail.com 


\section{Sports practice as an educational tool: working with values and resilience}

Simone Meyer Sanches

Kátia Rubio

University of São Paulo

\begin{abstract}
Brazilian society is currently facing the challenge of organizing and conducting massive sports events of large social impact. Within this context, the sport activity can be regarded as an efficient tool of psychosocial intervention, especially with children and youngsters. The present study aimed at the investigation of situations and experiences of high-performance athletes associated to the learning process that accompanied their insertion in this context and the values espoused therein. Interviews were carried out based on the life history method with four athletes belonging to two athletics teams from the State of São Paulo. Data were categorized, and the contents were analyzed qualitatively. The results pointed to various contributions of the insertion of these people into the sports context, some of them linked to external changes, such as the improvement of their aesthetic, financial or social inclusion status, and others related to internal or subjective aspects, such as the reinforcement and development of values of cooperation, friendship, solidarity, and the capacity to share and overcome adversities (resilience). The study concludes that sports activities, if well conducted (by well-prepared professionals), can both improve the practitioner's global development, and benefit the other environments in which he or she is inserted, such as family and peer group, thereby extending the contributions to the whole of society.
\end{abstract}

\section{Keywords}

Sports - Education - Values - Resilience.
Contact:

Simone Meyer Sanches Rua Dr. Ruy Vicente de Mello, 441 13083-745 - Campinas/SP si_sanches@hotmail.com 
Muito se tem discutido na atualidade sobre o potencial educativo do esporte e seus benefícios para o desenvolvimento físico, social e afetivo dos participantes. Porém, nota-se que frequentemente essas afirmativas são embasadas no senso comum e não se aprofundam na reflexão realizada, permanecendo com as ideias já difundidas de que $o$ esporte tira a criança da rua, o esporte ajuda a fazer novas amizades etc. Sabe-se que, quando a atividade esportiva é conduzida de maneira adequada por profissionais competentes e responsáveis, as afırmações supracitadas pelo senso comum fazem-se muito presentes; porém, as contribuições da inserção de um indivíduo nesse contexto podem ir muito além, beneficiando os praticantes em diversos campos de suas vidas. Tal atividade possui um potencial tão significativo que pode chegar a transformar a vida de uma criança, razão pela qual não podemos satisfazermo-nos com essas concepções genéricas e sem profundidade, que não abarcam todas as contribuições que a atividade esportiva pode trazer. É necessário aprofundarmo-nos, mergulharmos e inserirmo-nos nessa realidade para ampliarmos a reflexão.

Aqueles que se aventuram ou já se aventuraram por esse universo têm ou tiveram a oportunidade de perceber quanto a atividade esportiva pode ser cruel e excludente, sendo muitas vezes extremamente exigente e competitiva. Porém, seguramente também puderam conhecer o lado fascinante e apaixonante dessa prática. É por isso que o esporte pode ser considerado, nos dias atuais, como um dos fenômenos sociais de maior impacto em todo o mundo, fazendo com que indivíduos e nações compitam uns contra os outros, ao mesmo tempo em que une pessoas de uma forma como poucas outras atividades conseguem realizar. É nessa perspectiva que os jogos olímpicos, pan-americanos, mundiais e as copas do mundo tornaram-se megaeventos esportivos (RUBIO, 2007), que impactam as sociedades por onde passam e prendem a atenção do mundo, cujas nações mobilizam-se para assistir a esses atletas realizando feitos inacreditáveis, superando os limites do corpo e da mente humana e emocionando todos ao seu redor.

A psicologia do esporte atualmente compreende um dos campos que se está desenvolvendo de forma significativa e que já agrega um conhecimento científico importante, podendo contribuir para o alcance desses objetivos e beneficiar o praticante, caso a atividade seja conduzida de modo apropriado. Destaca-se a necessidade do aprofundamento da investigação a respeito de como a participação nessas atividades pode modificar, de uma forma mais significativa, a vivência do praticante. É preciso abordar questões relacionadas ao modo como tal vivência influencia na imagem e na avaliação que o esportista faz dele mesmo, e à forma como ele lida com as experiências inerentes a esse campo, que implicam situações de sucesso e fracasso, vitórias e derrotas constantes. 0 autoconhecimento das qualidades e dos pontos deficitários que todos apresentam é mais um aspecto a ser investigado nesse contexto; finalmente, interessa-nos compreender como se pode transpor os conhecimentos adquiridos por meio da atividade esportiva para outros contextos da vida.

A repercussão que essa atividade irá adquirir na vida do praticante dependerá da forma como é conduzida, pois ela pode apresentar um caráter tanto inclusivo, quanto extremamente excludente. Clara López (2005) destaca a mudança de valores ocorrida nesse contexto, cuja lógica da esportividade, do jogo limpo, do respeito ao rival e até da diversão e da noção de jogo muitas vezes é abandonada e substituída pela apologia da exacerbação da rivalidade e do vale-tudo (desde que não seja punido pelo árbitro), bem como da agressividade dentro e fora do terreno do jogo.

Porém, se essa prática for conduzida de acordo com as premissas da educação pelo esporte, ela pode contribuir imensamente para o desenvolvimento saudável do praticante. 0 esporte pode e deve ser considerado como uma das ferramentas mais eficazes para trabalhar com crianças e jovens, já que, além de ser uma 
atividade prazerosa e que traz diversos benefícios para a saúde física do praticante, ele desenvolve diversos valores que poderão ser transladados para outras esferas da vida dos esportistas. Guillermo Ruiz e Dolores Cabrera (2004) realizaram uma revisão bibliográfica na qual apontam diversos valores que podem ser trabalhados na educação física, citando, por exemplo, os identificados por Antonio Gómez Rijo (2003 apud RUIZ; CABREBA, 2004) - tolerância, integração, solidariedade, cooperação, autonomia, participação, igualdade - e os apresentados por Melchor Gutiérrez (1995 apud RUIZ; CABREBA, 2004), que diferencia os valores trabalhados por meio do esporte (vitórias e poder, esportividade e jogo limpo, expressão de sentimentos, companheirismo e diversão, habilidade e forma física) e da educação física (so- ciabilidade, êxito pessoal e de grupo, criatividade e cooperação, companheirismo e diversão, superioridade e autoimagem).

Llorenç Carreras et al. (2006) também contribuíram para o aprofundamento do tema, em sua obra ganhadora do prêmio Educación y Sociedad, na qual discorrem sobre diversos valores e propõem atividades facilitadoras na promoção dos mesmos. Entre os valores citados, percebe-se que muitos deles podem ser desenvolvidos e trabalhados por meio da prática esportiva, como a responsabilidade, a sinceridade, o diálogo, a confiança, a autoestima, a criatividade, a paz, a amizade, o respeito, a justiça, o compartilhar e, finalmente, a cooperação. Sobre este último aspecto, os autores apresentam uma figura que aponta outras variáveis relacionadas ao conceito de cooperação:

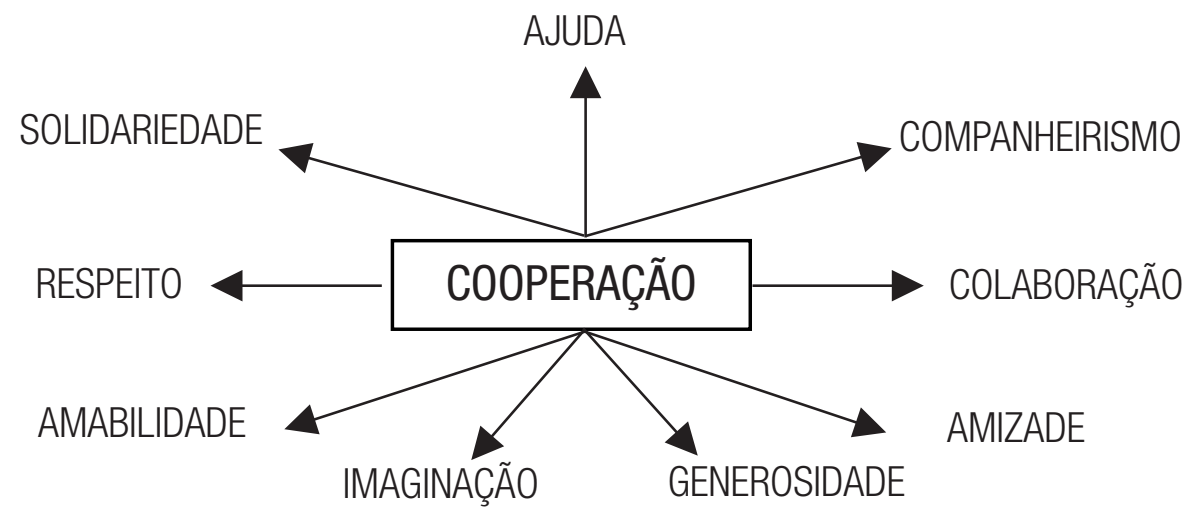

Figura 1 - Interação de alguns valores relacionados à cooperação (CARRERAS et al., 2006)

0 Brasil vive atualmente a expectativa pelos Jogos Olímpicos de 2016, situação que se constitui como uma grande oportunidade para a divulgação e a implementação, no maior número de escolas e instituições que trabalham com a atividade esportiva, dos valores olímpicos idealizados por Pierre de Freddy, mais conhecido como Barão de Coubertin. Segundo Kátia Rubio (2009), esse educador defendia e acreditava que o esporte era uma importante forma de educação para a juventude e sua preocupação era valorizar a competição leal e sadia, a saúde e a atividade física. (p. 8)

Em vez de valorizar o resultado final na disputa esportiva, ele enfatizava a importância da participação.

A partir do resgate da concepção dos jogos realizados na Grécia antiga, Coubertin 
reinventou os Jogos Olímpicos da era moderna, evento que tinha por objetivo criar oportunidades para a união e a participação de todos os países do mundo. Origina-se daí o termo olimpismo, que faz referência ao "conjunto de valores pedagógicos e filosóficos do Movimento Olímpico, e não apenas aos Jogos Olímpicos" (RUBI0, 2009, p. 8). Esses valores são descritos na Carta Olímpica, documento que preconiza a união da atividade esportiva com a cultura e a educação. Entre eles, destaca-se a oportunidade de promoção da paz entre diversas etnias, tornando possível "um tipo de disputa sem o uso da violência” (p. 10), marcado mais pela cooperação do que pela competição. Além disso, o olimpismo compreende o esporte como uma filosofia de vida que procura o equilíbrio entre corpo, mente e espírito, possibilitando o prazer no esforço despendido, o valor educacional dos exemplos positivos e da preservação da dignidade humana, sem qualquer tipo de discriminação e movido pelo espírito de amizade, solidariedade e fair play (ou jogo limpo).

Para que esses ideais possam ser implementados nas atividades esportivas de uma forma geral (desde a iniciação esportiva ou prática de tempo livre, até o esporte de alto rendimento), é necessário que a atuação do professor ou treinador esteja em consonância com a proposta educativa do esporte, principalmente em relação às idades escolares. Pedro Sáenz-López (2005) fez uma revisão de diversos autores que destacam o papel do educador e formador, o qual é considerado, especialmente na iniciação esportiva e nas categorias de base, como sendo a figura mais importante do universo esportivo e que exerce maior influência na motivação do praticante durante os primeiros anos de prática. Outros autores também citados nesse trabalho enfatizam o papel pedagógico de tal profissional e a importância de ele planejar as atividades adequadamente, utilizar técnicas de motivação apropriadas e comunicar-se de forma efetiva. Espera-se que ele seja entusiasmado, inquieto, criativo, organizado, consciente, interessado e capaz de se fazer respeitado. As atribuições do treinador são complementadas por Napoleón Murcia (1993 apud SÁENZ-LÓPEZ, 2005), que assevera que o profissional deve ser capaz de criar um ambiente que motive a criança a praticar, refletir, selecionar e descobrir as melhores formas de executar um movimento, de acordo com a finalidade deste.

Segundo Rubio et al. (2000), o professor/ treinador possui um papel de grande influência no contexto esportivo, contribuindo para a formação global dos esportistas. José Aníbal Marques e Sergio Kuroda (2000) reforçam tal premissa destacando que esse profissional pode ser um grande referencial para a formação de valores, a construção da cidadania e a preparação dos atletas para lidarem de forma mais adequada com os desafios enfrentados em diversos outros campos de suas vidas.

Diante dessas considerações, Urie Bronfenbrenner (1996) defende que o fator mais importante a ser estimulado é a qualidade das relações, explicitando que é fundamental que esse vínculo seja recíproco, bidirecional e estável. 0 autor também afirma que os eventos que mais influenciam no desenvolvimento de um indivíduo são as atividades realizadas com outras pessoas ou as que estas executam em sua presença. Dessa forma, evidencia-se a importância da qualidade do relacionamento estabelecido entre o atleta e seu professor/ treinador, destacando-se a responsabilidade de ambas as partes.

Sáenz-López (2005) complementa a reflexão sobre o tema afirmando que é necessário diferenciarmos níveis distintos da prática esportiva e seus respectivos objetivos, sendo que o esporte educacional é um deles. Este pode converter-se em um potente meio de educação sempre que for bem implementado; porém é imprescindível considerarmos que o desenvolvimento inadequado da prática esportiva pode ser igualmente prejudicial ao jovem praticante. A mesma premissa também pode ser aplicada à competição, que pode tanto acarretar repercussões positivas quanto negativas para o desenvolvimento do esportista. 0 autor ainda defende que 
o fair play pode ser assumido como um excelente recurso para desenvolvermos os valores do esporte, sendo que o professor possui um papel fundamental na transmissão dessa filosofia (SÁENZLÓPEZ, 2005)

Valter Bracht (2000/1) assevera que não podemos negar os benefícios que as práticas corporais aportam para a saúde de um indivíduo. Em sua revisão da literatura sobre o tema, Jan Janssens et al. (2004) concluíram que a prática regular de atividade física pode manter e aumentar de forma significativa as capacidades funcionais do praticante, além de preservar estruturas e retardar o processo de deteriorização corporal.

Robert Weinberg e Daniel Gould (2001) listaram alguns dos mecanismos psicológicos e fisiológicos citados por diversos pesquisadores como sendo responsáveis pelos efeitos positivos do exercício sobre o bem-estar psicológico. Dentre as explicações fisiológicas, estão: aumento no fluxo sanguíneo cerebral, mudança nos neurotransmissores cerebrais (por exemplo, norepinefrina, endorfınas, serotonina), aumento no consumo máximo de oxigênio e liberação de oxigênio para os tecidos cerebrais, redução na tensão muscular e mudanças estruturais no cérebro. Os autores destacam também os fatores psicológicos que podem auxiliar na inserção e na permanência dentro do contexto esportivo: dar um tempo ou esquecer problemas cotidianos, sensação aumentada de controle, sentimento de competência e de autoeficácia, interações sociais positivas e melhora no autoconceito e na autoestima.

Bracht (2000/1) defende que, apesar de ser fundamental considerarmos todos esses benefícios ofertados pela prática esportiva, não podemos restringir o sentido dessas atividades a tais objetivos, sendo necessário ampliarmos a discussão e considerarmos a atividade física como uma técnica utilizada como meio para atingir determinado fim.

Destaca-se a importância de considerarmos todos os ambientes em que o prati- cante está inserido, fazendo com que a intervenção na família também seja fundamental. Bronfenbrenner (1996) afirma que, durante a infância e a adolescência, as atividades e os relacionamentos mais significativos são aqueles mantidos com os pais, mas estes não são os únicos agentes de desenvolvimento dos indivíduos. Os adultos que interagem com a criança em outros ambientes além do familiar também podem contribuir ao complementarem o vínculo primário firmado nas relações familiares. Evidencia-se aqui a importância dos professores (da escola, de algum esporte, arte, música etc), dos funcionários da escola e dos vizinhos, que podem tornar-se pessoas próximas da criança e do adolescente, constituindo-se como pontos de referência com os quais o indivíduo poderá contar quando desejar e/ou necessitar, além de representarem fontes de aprendizado. Um dos fatores que contribuem para que o indivíduo tenha um desenvolvimento saudável é a necessidade de que haja uma consonância entre os valores adotados nos diferentes ambientes, para que se possa transitar entre eles com facilidade (BRONFENBRENNER, 1996). Dessa forma, espera-se que os valores trabalhados no contexto esportivo sejam fortalecidos e trabalhados nos outros ambientes que constituem a rede de apoio social e afetivo do indivíduo.

Ana Maria Capitanio (2003) corrobora essas premissas ao defender que o esporte, quando adotado numa abordagem educativa, pode tornar-se um excelente mecanismo para trabalhar com a formação integral e crítica do ser humano. A autora destaca que essa atividade pode ir muito além da ampliação dos conhecimentos técnicos e táticos do praticante, ao priorizar outros aspectos como cooperação, participação, solidariedade e criatividade dos alunos, os quais devem ser assumidos como sujeitos desse processo educativo, e não como meros reprodutores da modalidade esportiva praticada.

Entretanto, sabe-se também da delicadeza de tal tema e da necessidade de reflexão 
crítica do educador que se aventura nesse campo de atuação. Uma vez que o esporte envolve outras variáveis, como a competitividade, a vitória versus a derrota, a busca da glória etc., se estas não forem cuidadas, avaliadas e implementadas sob um olhar crítico e amplo, no interior de uma prática educativa, podem ser muito prejudiciais ao desenvolvimento de crianças e jovens (CAPITANIO, 2003).

O Programa Educação pelo Esporte, desenvolvido pelo Instituto Ayrton Senna (2004), criou a tecnologia da educação pelo esporte para o desenvolvimento humano, que reúne princípios e metodologias com vistas a transformar potenciais em competências cognitivas, produtivas, relacionais e sociais. 0 programa tem como objetivo principal fazer com que as crianças e os jovens participantes sejam capazes de compreender a realidade na qual estão inseridos, estabelecer metas e sonhos a serem alcançados, praticar sua cidadania e tornarem-se agentes transformadores de suas próprias vidas e de suas comunidades.

A avaliação do Programa foi realizada a partir da coleta de dados por meio de entrevistas semiestruturadas (abertas) individuais e grupais, questionários autoaplicáveis, entrevistas e testes estruturados, aplicados às crianças, aos adolescentes e a seus familiares, aos educadores dos projetos parceiros e aos professores das escolas. Foram coletadas informações provenientes também de dados oficiais sobre educação (índices de evasão escolar), documentos dos projetos (ficha de inscrição, frequência, projetos pedagógicos etc.) e registros das escolas (boletins, frequências etc.).

Os resultados apontam para as contribuições do esporte como ferramenta de educação integral das novas gerações, auxiliando na preparação desses jovens para o enfrentamento de desafios no âmbito pessoal, social e profissional. 0 programa baseia-se nos quatro pilares de educação da UNESCO - aprender a conhecer, aprender a fazer, aprender a conviver, aprender a ser - e assume o esporte como uma atividade utilizada para desenvolver não apenas a dimen- são física, mas também os aspectos cognitivos, emocionais e sociais dos participantes.

Os resultados da avaliação desse programa indicaram que as crianças e adolescentes com mais de um ano de participação no Programa (grupo principal; N=338) apresentavam um número maior de posturas positivas do que aqueles que tinham ingressado no projeto havia dois meses ou menos (grupo controle; $\mathrm{N}=172$ ). Tais resultados foram classificados nas seguintes categorias (INSTITUTO AYRTON SENNA, 2004):

1. melhora no relacionamento com a família e com outras pessoas;

2. participação e desempenho escolar mais satisfatórios;

3. responsabilidade, organização e disciplina crescentes;

4. amadurecimento e desenvolvimento pessoal e social;

5. vencimento da timidez e/ou segurança e maior participação;

6. diminuição de comportamento agressivo e rebelde;

7. melhora no desenvolvimento físico e na saúde;

8. aumento da autoestima;

9. melhora no desempenho no trabalho em grupo;

10. saída da rua e acesso a um lugar adequado de permanência.

0 autoconhecimento também é um dos aspectos que podem ser desenvolvidos por meio da prática esportiva. Segundo Luis Helena Trombeta (2000), esse é um dos fatores relacionados à resiliência, podendo ser considerado como um fator de proteção, conceito que se refere aos aspectos que podem auxiliar positivamente no desenvolvimento de um indivíduo. É fundamental que o indivíduo conheça suas qualidades e limitações para que possa adaptar suas expectativas e evitar frustrações, como estabelecer metas muito distantes de suas possibilidades reais ou não reconhecer o 
momento de interromper ou diminuir a carga do treinamento, resultando em uma lesão. Portanto, a atividade esportiva pode auxiliar tanto as crianças quanto os jovens e adultos praticantes a conhecerem suas potencialidades e as dificuldades a serem trabalhadas, contribuindo, assim, para a melhora do rendimento esportivo e pessoal desses indivíduos.

Manuel Tubino (1996) destaca alguns dos princípios mais importantes que devem ser adotados por iniciativas que tenham como objetivo desenvolver um trabalho orientado para a educação pelo esporte. São eles:

1. 0 princípio da totalidade: a prática esportiva deve fortalecer a unidade do homem consigo, com o outro e com o mundo, fortalecendo o conhecimento, a autoestima e a autossuperação, em um ambiente de respeito e preservação das individualidades.

2. 0 princípio da coeducação: integração, por meio do esporte, de situações heterogêneas de sexo, idade, nível socioeconômico, condições físicas etc., dos praticantes da atividade esportiva.

3. princípio da cooperação: promover ações conjuntas para a realização de objetivos comuns durante a prática do esporte, principalmente em situações de individualismo.

4. 0 princípio da emancipação: tem por objetivo levar os participantes a situações estimulantes de desenvolvimento de independência, autonomia e liberdade.

5. 0 princípio do regionalismo: focaliza situações de respeito, proteção e valorização das raízes e heranças culturais.

Tubino (1996) também assume a prática esportiva como uma atividade que pode contribuir para a formação integral do ser humano, sendo que ela não somente se relaciona ao desenvolvimento físico do participante, mas também exerce grande repercussão em suas funções psicológicas (emocionais) e sociais (relacionais).
0 autor destaca que essa atividade é importante nas fases iniciais do desenvolvimento, mas também se constitui como um modelo de educação permanente, que se estenderá por toda a vida da pessoa e, portanto, continuará beneficiando-a ao longo do tempo. Os valores educativos do esporte podem ser encontrados desde nos primeiros anos de vida do indivíduo, favorecendo seu desenvolvimento motor e psicomotor, passando pelo processo de socialização próprio do esporte e da atividade física na idade escolar, seguindo com os benefícios ofertados ao praticante jovem e na meia-idade (sendo utilizado, algumas vezes, como forma de relaxamento do estresse cotidiano, e, em outras, como ocupação do tempo ocioso, além da busca de um espaço de socialização e manutenção da saúde e da boa aparência física etc.), até ser considerado um excelente meio de estimulação do ânimo e da ativação psicossocial na terceira idade.

A atividade esportiva também pode ser utilizada como uma forma de canalizar a energia que muitas crianças têm dificuldade de controlar, evitando que elas depositem esse vigor, natural de toda criança e de todo jovem em pleno processo de desenvolvimento, em situações inapropriadas. As escolas frequentemente apresentam queixas relacionadas à indisciplina, e não é incomum que os profissionais dessas instituições denominem tais alunos de hiperativos, adotando assim uma "concepção que entende a queixa escolar como um problema individual, pertencente à criança encaminhada" (PROENÇA, 1997, p. 31).

Beatriz Souza (2004) corrobora essa discussão ao defender que a necessidade de brincar da criança é irreprimível, e caso a instituição não permita que a criança brinque, ela irá procurar outros canais para manifestar essa necessidade, como a bagunça. É o que ocorre quando o conteúdo escolar trabalhado em sala de aula estiver muito fácil e a criança já dominar a matéria que está sendo ensinada: o resultado será o desinteresse e a busca por outras ocupações (conversar, incomodar o colega 
etc.), resultando na indisciplina. A atividade esportiva pode apresentar-se, nesse contexto, como uma estratégia eficaz para lidar com as crianças, que necessitam estar inseridas em atividades que sejam motivadoras e que despertem seus interesses.

Dessa forma, evidencia-se a relevância social do tema abordado, que pode ser complementada pela necessidade de desenvolvimento da área no âmbito acadêmico. Na psicologia do esporte, percebe-se que, ao longo dos anos, o interesse por tal campo e linha de trabalho está aumentando progressivamente, porém, ainda há muito o que ser feito. Até os dias atuais, tanto na esfera da prática profissional quanto na da pesquisa científica, ainda se percebe a predominância do interesse pelo esporte de alto rendimento. A análise realizada por Simone Meyer Sanches (2004) sobre os anais do X Congresso Brasileiro e III Congresso Internacional de Psicologia do Esporte (2003) concluiu que, dos 83 trabalhos publicados, 75 tratavam de temas relacionados ao esporte de alto rendimento, seis relacionavam o esporte à qualidade de vida, e somente dois trabalhos tratavam do esporte com uma perspectiva social/educacional. Em 2009, Sanches analisou o programa do IX Congresso Sul-Americano de Psicologia do Esporte, realizado em Belo Horizonte em outubro de 2008. Os resultados indicam que, dentre as vinte conferências e mesas redondas oferecidas no evento, apenas quatro abordavam temas relacionados ao esporte educacional ou à qualidade de vida (SANCHES, 2009).

Pode-se supor que tal fato se deve ao status que o esporte de alto rendimento possui em nossa sociedade contemporânea, refletindo a busca pelo destaque na mídia e o retorno financeiro que aparecem (pelo menos no imaginário de grande parte das pessoas) atrelados ao esporte profissional.

0 contexto esportivo, de um modo geral, considerando-se suas diferentes abordagens (esporte de alto rendimento, iniciação esportiva, esporte adaptado, lazer/prática de tempo livre, qualidade de vida, esporte escolar, projetos sociais ou reabilitação), apresenta ao praticante uma série de situações adversas e de obstáculos a serem superados, como a alta exigência nos treinamentos, a pressão e a cobrança internas e externas por resultados, a necessidade de lidar com a dor proveniente dos treinamentos e de lesões, e com as situações constantes de avaliação.

A partir dessas situações, o praticante deve buscar encontrar e/ou desenvolver recursos internos e externos para lidar com as adversidades, processo associado ao conceito de resiliência, que se refere à "capacidade humana para enfrentar, sobrepor e ser fortalecido ou transformado por experiências de adversidade" (GROTBERG, 2002, p. 20). A análise da produção bibliográfica das pesquisas relacionadas a esse conceito, realizada por Marileide de Oliveira et al. (2008), destacou que "se trata de um somatório de processos de naturezas social e psíquica que permitem o desenvolvimento sadio, mesmo em contexto não sadio" (p. 756). As autoras ainda destacam a característica interacionista desse fenômeno, que será determinado na relação que o sujeito estabelece com o meio no qual está inserido. Sanches (2009) afirma que a capacidade de superar adversidades pode ser considerada mais um aspecto a ser desenvolvido por meio da prática esportiva, já que esta oferece diversas situações consideradas de risco, mas também estimula o indivíduo a criar recursos internos e externos para lidar com os obstáculos.

Se, na área acadêmica, o esporte de alto rendimento ainda possui maior visibilidade, o contexto de intervenções práticas reflete outra realidade. Os projetos e as instituições que utilizam o esporte como ferramenta educativa estão ampliando-se no Brasil, conforme apontado por Sanches (2004), e o número de iniciativas governamentais e não governamentais que investem na prática esportiva como uma alternativa de trabalho, visando à minimização dos diversos problemas sociais enfrentados no mundo atual, tem crescido significativamente. Evidencia-se, mais uma vez, a necessidade do desenvolvimento de trabalhos que forneçam uma fundamenta- 
ção teórica para embasar, de modo consistente, tais iniciativas práticas, tendo por objetivo aprofundar os trabalhos realizados e beneficiar ainda mais os participantes desse contexto.

0 estudo apresentado consiste em uma pesquisa qualitativa, pois, segundo Joel Martins e Maria Aparecida Bicudo (1989), busca investigar não somente os fatos, mas os fenômenos, que são definidos como "aquilo que se mostra em si mesmo, o manifesto" (p. 22). Os autores ainda reforçam que, no caso de pesquisas psicológicas e educacionais, tal conceito deve assumir o sentido de "entidade que se mostra em um local situado” (p. 22).

Maria Cecília Minayo (2007) complementa esse raciocínio afirmando que a pesquisa qualitativa trabalha com o universo dos significados, motivos, aspirações, crenças, valores e atitudes, que são compreendidos como parte de uma realidade social mais ampla. Essa mesma visão norteou a escolha do método de análise dos dados, que consistiu na análise de conteúdo desenvolvida por Laurence Bardin (1977). Segundo essa autora, a análise de conteúdo pode ser entendida como:

um conjunto de técnicas de análise das comunicações visando obter, por procedimentos sistemáticos e objetivos de descrição do conteúdo das mensagens, indicadores (quantitativos ou não) que permitam a inferência de conhecimentos relativos às condições de produção/recepção (variáveis inferidas) destas mensagens. (p. 42)

Dessa forma, a pesquisa em questão apresenta a análise de casos individuais, buscando uma compreensão particular do objeto estudado a partir dos relatos dos participantes, e possibilitando uma discussão sobre o contexto social que permeia a realidade dos sujeitos e da sociedade mais ampla.

\section{Objetivo}

Este estudo teve como objetivo investigar situações e vivências de atletas de alto rendimento relacionadas ao aprendizado decorrente da inserção no contexto esportivo e aos valores ali preconizados.

\section{Método}

\section{Participantes}

Foram entrevistados quatro atletas de alto rendimento (três homens e uma mulher) da modalidade atletismo, provenientes de duas equipes do interior do Estado de São Paulo. A seleção dos participantes atendeu aos seguintes critérios: os atletas deveriam ser profissionais inseridos no esporte de alto rendimento há pelo menos dez anos e com participação em grandes competições esportivas, como campeonatos mundiais e jogos olímpicos.

\section{Instrumento}

Optou-se pelo método qualitativo devido à possibilidade de este fornecer uma compreensão mais profunda dos fenômenos sociais, destinando uma maior relevância ao aspecto subjetivo da ação social diante da configuração das estruturas societais e valorizando as especificidades do objeto estudado (HAGUETTE, 2007). No presente trabalho, foram realizadas entrevistas por meio do método de história de vida, no qual o participante narra sua vida, transmitindo sua interpretação sobre o fato social vivenciado de uma forma individual, mas também fornece elementos sobre o momento histórico em questão e sobre as instituições com as quais se relacionou (RUBI0, 2006). Realizou-se uma coleta piloto de dados com um atleta que atendia aos critérios estabelecidos, para posterior aplicação do método com os participantes da pesquisa.

\section{Procedimento}

Foi estabelecido contato com duas instituições esportivas de alto rendimento e requisitou-se a assinatura do termo de consentimento 
institucional. Em seguida, o pesquisador contatou os participantes, explicando o objetivo da pesquisa e solicitando a assinatura do termo de consentimento livre e esclarecido (caso os atletas estivessem de acordo com a participação), o qual autorizava a gravação das entrevistas. Estas foram realizadas individualmente nos próprios clubes esportivos, em local reservado, e os relatos foram transcritos e analisados qualitativamente. Realizou-se uma categorização das falas de acordo com os preceitos da análise de conteúdo (BARDIN, 1977), sendo estas agrupadas segundo a temática abordada na fala analisada.

\section{Resultados e discussão}

Abordaremos, no presente trabalho, os aspectos relacionados aos valores preconizados ao longo da vivência dos participantes no contexto esportivo e as experiências relatadas que podem ser associadas a uma abordagem educacional da prática esportiva.

0 primeiro ponto a ser destacado na fala dos participantes é a reflexão sobre o significado e o aprendizado decorrentes da situação competitiva. Sabe-se que a competitividade é um aspecto muito presente não somente no contexto esportivo, mas na vida dos seres humanos de um modo geral, especialmente na sociedade contemporânea. Principalmente na adolescência, a competição entre pares é um fator de grande importância; se for bem canalizada, ela pode contribuir para o progresso de todos os envolvidos na situação competitiva, desde que esta seja conduzida de forma apropriada e respeitando os limites dos integrantes. A competitividade intrínseca ao contexto esportivo foi um dos aspectos mencionados nas falas dos atletas entrevistados, como destacado a seguir:

Aí chegou no Brasileiro apareceu um menino lá [...] "Nossa, quem que é esse cara grandão”, era bom, tava fazendo uns resultados bons lá, [...] "Não é possível, ele vai ganhar de mim" [...] Terminou o Brasileiro, terminei em segundo lugar [...] "Nossa, perdi", esse atleta bateu o recorde brasileiro, mas, assim, eu fiquei meio emburrado com ele por eu ser o primeiro e ele chegou assim do nada.

0 constante surgimento de atletas mais competentes ou, pelo menos, concorrentes pode ser considerado uma das adversidades pertencentes ao mundo esportivo com a qual os atletas devem aprender a lidar de forma saudável, para que isso não se transforme em um obstáculo insuperável que gere desmotivação e uma consequente queda no rendimento. Nesse caso, a situação pode ser considerada como potencialmente educativa, já que irá desenvolver uma competência passível de ser transladada para outros contextos de vida.

A competitividade na sociedade contemporânea pode ser um fator desencadeador de estresse. É possível aplicar essa premissa a diversos contextos, como situações profissionais ou interpessoais nas quais o indivíduo que obtiver um maior destaque ou apresentar resultados mais satisfatórios será mais valorizado.

A experiência esportiva pode proporcionar o aprendizado de que os resultados finais são situacionais e não oferecem garantia de continuidade, já que dependem de uma série de fatores internos e externos ao indivíduo que nem sempre estão sob seu controle. Evidencia-se, mais uma vez, a interação entre os fatores individuais e ambientais, pois a obtenção de bons resultados acontece a partir da união de fatores genéticos e constitucionais do indivíduo com os aspectos do ambiente no qual ele está inserido - por exemplo, no contexto esportivo, as circunstâncias de treinos e competições, condições climáticas, preparação física, técnica, tática e psicológica do competidor e do adversário. Portanto, preconiza-se que o indivíduo compreenda a importância de direcionar sua autoavaliação, suas cobranças e expectativas apenas sobre sua preparação, que deverá englobar o processo vivenciado e não somente o resultado final. 
Retomando a discussão a respeito da situação competitiva, entende-se que ela não deve ser considerada como intrinsecamente negativa, podendo ser trabalhada atrelada aos valores da cooperação, os quais, segundo Carreras et al. (2006), referem-se a ajuda, solidariedade, companheirismo, colaboração, amizade, generosidade, imaginação, amabilidade e respeito. 0 relato a seguir aponta para diversas situações propiciadas por meio da prática esportiva que evidenciam a manifestação dessas atitudes entre os colegas de equipe ou entre os próprios competidores:

Fui conversando, peguei uma amizade com ele [outro competidor da mesma prova $]^{1}$, porque é uma prova longa, demora dois dias, então você vai pegando uma amizade, daí [ele] falou: "pô, meu professor me falou que se eu correr tanto eu bato o recorde brasileiro" [...] "deixa eu ver quanto ele falou que é”, eu olhei lá, e disse: "Eu tenho esse resultado - 2" 45 no $1.000 \mathrm{~m}[. .$.$] eu tenho esse resultado e$ tenho melhor, se você correr e conseguir correr perto de mim você provavelmente vai bater o recorde, eu vou do seu lado e vou te ajudando, vou gritando, e você bate esse recorde, aí já que dá pra bater, era de um uruguaio mesmo pelo menos fica com um brasileiro", "É, mas será que dá? Eu tenho 2"50, para correr 2"45 eu não vou conseguir", "Não, vai sim, vamos lá, que se você correr atrás de mim, a hora que você cansar você fecha o olho e sai correndo, aí no meio da prova nós lá correndo, e eu gritando na reta de chegada, vai, vai" [...] eu fui correndo do lado dele, eu gritando pra ele, torcendo pra ele, eu que tava com raiva dele no começo, no final da prova eu tava torcendo pra ele, "Vai, vamo, vamo, vamo, vamo", aí chegou, bateu

1- Todas as observações inseridas entre colchetes nas falas dos entrevistados foram adicionadas pelas autoras, objetivando facilitar a compreensão do conteúdo dos trechos citados. o cronômetro 2"43. "Nossa, consegui, obrigada". Depois disso aí ele ficou meu amigo, a gente não tinha mais bronca.

Esse depoimento demonstra a amizade e a colaboração que foram consolidando-se entre o atleta entrevistado e seu principal adversário durante a competição, situação na qual, ao fornecer apoio e incentivo a outro esportista num momento em que este necessitava de estímulo, o sentimento de rivalidade transformou-se em companheirismo e solidariedade. A quebra do recorde foi identificada como meta comum a ser alcançada e a rivalidade entre os competidores converteu-se em um sentimento de identificação por eles serem da mesma nacionalidade e estarem representando o mesmo país. Naquele momento, o coletivo prevaleceu perante o individual, e fazer com que o recorde da prova passasse a ser de um brasileiro significou uma ação conjunta, em prol de um mesmo objetivo. Os dois uniram-se durante a prova para alcançarem a meta estabelecida, conquistando o êxito almejado. Nesse caso, a união dos dois atletas tornou-se um fator de proteção que inclusive repercutiu de forma positiva no resultado esportivo de ambos. Outra situação relatada pelo participante ilustra uma circunstância semelhante:

$\mathrm{Na}$ segunda prova, ele [adversário] machucou, no salto em distância, aí eu falei: "Pô...", não fiquei nem feliz, [...] porque ele tinha resultado melhor, porque eu já tinha feito uma amizade com ele, então eu fiquei até triste por ele, porque, "Puxa, ele machucou, agora só vai dar pra ir um pro pódio".

Novamente aqui, o objetivo coletivo (de representantes de um mesmo país) prevaleceu sobre a meta individual, sobre o desejo de ambos os atletas de conquistar um espaço no pódio. Nesse caso, a rivalidade foi vencida pela amizade, um dos valores descritos por Carreras et al. (2006) e por Rubio (2009). 
Outra situação relatada por um dos atletas entrevistados, atrelada à possibilidade do estabelecimento de vínculos de amizade e companheirismo entre os indivíduos inseridos no ambiente esportivo, pode ser observada a seguir:

Eu tinha minhas amizades assim lá, mas eu era muito mais próxima das meninas da ginástica do que as da escola. Por exemplo, se eu tinha que sair, eu saía com as meninas da ginástica, não com as da escola. [...] Eu sou bem tímida, então não sou de me abrir muito, e eu acho que eu passava muito mais tempo com as meninas da ginástica do que com as da escola né? É, e por exemplo, a ginástica a gente viajava muito, desde pequena a gente viajava junto, então acabou tendo um vínculo maior por isso.

A participante mostra como a inserção no ambiente esportivo favorecia uma relação de companheirismo (CARRERAS et al., 2006), desta vez estabelecida ao longo do processo de treinamentos e competições. Além disso, esse contexto facilitou que a atleta trabalhasse sua timidez e sua segurança, participando com mais afınco das atividades grupais, aspecto que está em consonância com os resultados encontrados pelo Instituto Ayrton Senna (2004) como uma das posturas positivas estimuladas por meio do Programa Educação pelo Esporte por eles desenvolvido.

A interação propiciada pela atividade praticada também contribuiu para que houvesse uma identificação entre as ginastas, por terem elas interesses em comum e um ritmo de desenvolvimento mais semelhante, influenciado pela grande dedicação ao esporte:

Mas acho que é porque a gente pensava mais parecido, a gente acho que, quem faz esporte acho que demora um pouco mais assim pra crescer mesmo, pra sei lá, pensar em namorar, acho que o esporte dá, não sei, principalmente a ginástica, a gente era mais "criançona" assim, eu era mais "criançona” do que o pessoal da escola, eu via isso [...] com o pessoal da ginástica assim era mais parecido.

Os relatos também comprovam a importância do papel do professor/treinador para a formação esportiva e pessoal dos atletas, como já destacado por Rubio et al. (2000) e por Marques e Kuroda (2000). 0 trecho seguinte comprova a importância que o vínculo com o professor/treinador pode assumir em decorrência do tempo de convivência (muitas vezes, diária):

Meu professor de educação física [...] eu acho assim, as pessoas importantes na vida de outras pessoas tem uma certa hierarquia né, primeiro a Deus, segundo é a família, terceira as pessoas que estão em contato direto com você, quem seria, os treinadores, eu coloquei primeiro plano Deus, em segundo a família, em terceiro tem que ser o treinador porque a gente fica muito tempo mais próximo do treinador do que com a família.

Dessa forma, percebe-se que o ambiente esportivo pode propiciar diversos benefícios para o desenvolvimento social e afetivo do participante. A pesquisa desenvolvida por Sanches (2004) comprovou que a inserção no projeto social pesquisado, o qual utiliza a prática esportiva como principal ferramenta de trabalho, contribuiu para o aumento da rede de apoio social e afetivo dos participantes, promovendo a vinculação entre os próprios atletas e com os professores/treinadores.

Os relatos reforçam a importância da qualidade das atividades propostas pelos professores ao destacarem a necessidade de esses profissionais oferecerem atividades atrativas e que venham ao encontro das necessidades das crianças, como explicitado na situação descrita a seguir:

0 professor na escola que descobria que eu tinha que gastar meu tempo se dava bem comigo, os outros não, porque eu sempre fui assim na escola, eu tinha facilidade, 
considerado aquele inteligente da sala, porém bagunceiro, eu fazia as coisa rapidinho assim, fazia rapidinho, e depois não tinha nada pra fazer aí eu bagunçava.

0 esporte pode ser considerado, nesse caso, uma excelente forma de canalizar a energia da criança para uma atividade saudável, prevenindo que ela se manifeste de um modo inadequado, conforme discussão realizada por Beatriz Souza (2004) e Marilene Proença (1997).

Podemos destacar, ainda, conforme apontado por Rubio (2009), outros valores preconizados no contexto esportivo, como o respeito a si mesmo, ao seu corpo e ao outro, bem como o fair play, o espírito de superação, o direito de igualdade e de justiça. A autora afırma que o esporte pode contribuir para a formação do caráter a partir do autoconhecimento, do autocontrole e da autorrealização. Este último aspecto está presente na fala de um dos atletas olímpicos entrevistados:

Independente se fosse ouro, prata ou bronze, eu tinha alcançado o meu objetivo. E aquele momento ali, passou a ser o momento mais feliz da minha carreira.

0 autocontrole e o desenvolvimento do senso de responsabilidade também aparecem nos relatos dos participantes como aspectos trabalhados por meio da prática esportiva, como se pode verificar a seguir:

Você tem que se controlar [...] você é o responsável direto pelos seus atos.

0 relato seguinte explicita a importância do conhecimento do funcionamento e dos limites do corpo, conforme já destacado por Trombeta (2000), especialmente no caso de atletas profissionais, quando o corpo torna-se o principal objeto de trabalho:

Eu sempre soube respeitar o meu corpo [...] Eu não tive lesões significativas, ou posso falar nenhuma lesão, bom, primeiro porque eu sempre soube o que é um organismo, e segundo que eu já estudava, já tava na faculdade.

Os atletas entrevistados destacam as contribuições que a prática esportiva trouxe para o fortalecimento da autoestima, ao possibilitar a demonstração de suas habilidades físicas, e do reforço social decorrente do bom desempenho, como evidenciado na fala a seguir:

Ele [professor de educação física] me levou para uma competição escolar, eu lembro que pra mim foi muito legal, salto em distância na época [...] eu ganhei o salto em distância e já arrumei uma namorada. [...] Eu ganhei um salto em distância e já fiquei bonito, aí fui ganhei $1000 \mathrm{~m}$ [...] e aí pronto, era o atleta mais completo da escola [...] esporte coletivo era fácil, uma vez que tinha condicionamento físico, tinha facilidade aprender técnica [...] virei o cara mais bonito da escola, comecei a namorar quem eu queria, independente de ser negro, ser branco, da menina ser negra, ser branca, então eu comecei a entender que o esporte transforma muitas coisas.

\section{Conclusão}

A partir da análise das histórias de vida e das experiências relatadas pelos atletas participantes, pode-se concluir que, mais importante do que as transformações externas (por exemplo, a melhora da condição estética, financeira ou de inclusão social), as principais contribuições da inserção no contexto esportivo foram relacionadas, em todos os casos investigados, aos aspectos internos e subjetivos, como o reforço e o desenvolvimento de valores de cooperação, amizade e solidariedade, bem como a capacidade de compartilhar e de superar adversidades (resiliência).

É necessário destacar que, para que esses aspectos possam ser trabalhados de forma que 
sejam introjetados e incorporados pelos participantes em seus relacionamentos com os mais diversos campos de suas vidas, é necessário que seja priorizada a intervenção com os ambientes que compõem a rede de apoio social e afetivo do indivíduo. Dessa forma, evidencia-se a importância de trabalharmos com o grupo de iguais, ou seja, com o comportamento dos outros integrantes/praticantes da atividade esportiva de forma que os valores trabalhados sirvam de modelo e sejam adotados por todos.

Além disso, é fundamental o investimento na capacitação profissional dos professores que irão atuar com esses jovens, para que aqueles possam respeitar as etapas do desenvolvimento dos praticantes, bem como suas necessidades e possibilidades, realizando um trabalho que os beneficie num período compreendido tanto a curto, quanto a médio e a longo prazo.

Deve-se destacar, porém, que essas intervenções não serão efetivas se a família não participar de tal processo, transmitindo valores coerentes com os trabalhos no contexto esportivo. Sabe-se que a família é o principal modelo e agente de formação de valores, crenças, atitudes e comportamentos; portanto, ela deve ser a primeira a preocupar-se com o processo de educação de seus filhos, fazendo com que o contexto esportivo seja um ambiente que com- plemente e auxilie na formação e no desenvolvimento dos participantes.

Conclui-se que a atividade esportiva pode ser considerada como uma ferramenta eficiente de intervenção psicossocial, contribuindo para o desenvolvimento físico, social, emocional e moral dos participantes. Isso se torna possível quando as atividades são ministradas por profissionais competentes e comprometidos com a evolução de cada aluno, respeitando o estágio de desenvolvimento em que ele se encontra. Destaca-se a relevância dessa temática, especialmente em uma sociedade que apresenta inúmeras dificuldades de ordem social e que está prestes a vivenciar megaeventos esportivos de repercussão mundial, os quais certamente contribuirão para a valorização da atividade esportiva, captando a atenção da mídia e de um número significativo de telespectadores. Nesse contexto, o potencial de atratividade do esporte irá aumentar ainda mais, fortalecendo-o, assim, como estratégia de intervenção, especialmente com crianças e jovens.

Ao trabalharmos com essa população, estamos investindo em programas de intervenção primária, evitando que diversos problemas venham a concretizar-se, contribuindo para o desenvolvimento global dos indivíduos praticantes e ampliando os benefícios para suas famílias e para a sociedade de modo geral. 


\section{Referências}

BARDIN, Laurence. Análise de conteúdo. Lisboa: Edições 70, 1977.

BRACHT, Valter. Esporte na escola e esporte de rendimento. Movimento, Porto Alegre, v. 6, n. 12, p. 14-24, 2000/1.

BRONFENBRENNER, Urie. A ecologia do desenvolvimento humano: experimentos naturais e planejados. Porto Alegre: Artmed, 1996.

CAPITANIO, Ana Maria. Educação através da prática esportiva: missão impossível? Revista Digital, Buenos Aires, ano 8, n. 58, mar. 2003. Disponível em: <http://www.efdeportes.com/efd58/esport.htm>. Acesso em: 6 fev. 2009.

CARRERAS, Llorenç et al. Cómo educar en valores: materiales, textos, recursos y técnicas. 14. ed. Madrid: Narcea, 2006.

GROTBERG, Edith. Nuevas tendencias en resiliencia. In: MELILLO, Aldo; SUÁREZ, Elbio Néstor (Orgs.). Resiliencia: descubriendo las propias fortalezas. Buenos Aires: Paidós; 2002. p. 19-30.

GUTIÉRREZ, Melchor. El valor del deporte en la educación integral del ser humano. Revista de Educación, Madrid, n. 335, p. 105-126, set.-dez. 2004.

HAGUETTE, Teresa Maria Frota. Metodologias qualitativas na sociologia. Petrópolis: Vozes. 2007.

INSTITUTO AYRTON SENNA. Educação pelo esporte: educação para o desenvolvimento humano pelo esporte. São Paulo: Saraiva, 2004.

JANSSENS, Jan et al. Education through sport: an overview of good practices in Europe. Holanda: W. J. H. Mulier Institute, 2004.

LÓPEZ, Clara. El concepto mujer y la educación en valores a través del deporte. In: CARRIZOSA, Manuel Vizuete.; PRECIADO, Ventura García (Coords.). Valores del deporte en la educación (año europeo de la educación a través del deporte). Madrid: Ministerio de Educación y Ciencia, 2005. p. 79-106. (Colección Aulas de Verano, Série Humanidades)

MARQUES, José Anibal Azevedo; KURODA, Sérgio Junichi. Iniciação esportiva: um instrumento para a socialização e formação de crianças e jovens. In: RUBIO, Kátia (Org.). Psicologia do esporte: interfaces, pesquisa e intervenção. São Paulo: Casa do Psicólogo, 2000. p. 125-137.

MARTINS, Joel; BICUDO, Maria Aparecida Viggiani. A pesquisa qualitativa em psicologia: fundamentos e recursos básicos. São Paulo: Moraes/EDUC, 1989.

MINAYO, Maria Cecília de Souza (Org.). Pesquisa social: teoria, método e criatividade. Petrópolis: Vozes, 2007.

OLIVEIRA, Marileide A. et al. Resiliência: análise das publicações no período de 2000 a 2006. Psicologia Ciência e Profissão, Brasília, v. 28, n. 4, p. 754-767, 2008.

PROENÇA, Marilene. A queixa escolar e o predomínio de uma visão de mundo. In: MACHADO, Adriana Marcondes; SOUZA, Marilene P. Rebelo (Orgs.). Psicologia escolar: em busca de novos rumos. São Paulo: Casa do Psicólogo, 1997. p. 19-37.

RUBI0, Kátia. Medalhistas olímpicos brasileiros: memórias, histórias e imaginário. São Paulo: Casa do Psicólogo, 2006.

Megaeventos esportivos, legado e responsabilidade social. São Paulo: Casa do Psicólogo, 2007.

Esporte, educação e valores olímpicos. São Paulo: Casa do Psicólogo, 2009.

RUBI0, Kátia. et al. Iniciação esportiva e especialização precoce: as instâncias psicossociais presentes na formação esportiva de crianças e jovens. Revista Metropolitana das Ciências do Movimento Humano, São Paulo, ano 4, v. 4, n. 1, p. 52-61, 2000. 
RUIZ, Guilhermo; CABRERA, Dolores. Los valores en el deporte. Revista de Educación, Madrid, n. 335, p. 9-19, set.-dez. 2004.

SÁENZ-LÓPEZ, Pedro. El deporte como contenido y práctica educativa. In: CARRIZOSA, Manuel Vizuete.; PRECIADO, Ventura Gárcia (Coords.). Valores del deporte en la educación (año europeo de la educación a través del deporte). Madrid: Ministerio de Educación y Ciencia, 2005. p. 29-61. (Colección Aulas de Verano, Série Humanidades)

SANCHES, Simone Meyer. Prática esportiva e desenvolvimento social e afetivo: projetos sociais como rede de apoio. 2004. Dissertação (Mestrado) - Instituto de Psicologia, Pontifícia Universidade Católica de Campinas, Campinas, 2004. Paulo, 2009.

Resiliência e prática esportiva. 2009. Tese (Doutorado) - Faculdade de Educação, Universidade de São Paulo, São

SOUZA, Beatriz Paula. Professora desesperada procura psicóloga para classe indisciplinada. In: MACHAD0, Adriana Marcondes; SOUZA, Marilene P. Rebello (Orgs.). Psicologia escolar: em busca de novos rumos. 4. ed. São Paulo: Casa do Psicólogo, 2004. p.105-112.

TROMBETA, Luisa Helena A. Padula. Resiliência em adolescentes: estudo preliminar de variáveis e medida. 2000. Dissertação (Mestrado) - Instituto de Psicologia, Pontifícia Universidade Católica de Campinas, Campinas, 2000.

TUBINO, Manuel José Gomes. 0 esporte educacional como uma dimensão social do fenômeno esportivo no Brasil. In: CONFERÊNCIA BRASILEIRA DE ESPORTE EDUCACIONAL. Memórias: Conferência Brasileira de Esporte Educacional. Rio de Janeiro: Editoria Central da Universidade Gama Filho, 1996. p. 9-16.

WEINBERG, Robert S.; GOULD, Daniel. Fundamentos da psicologia do esporte e do exercício. 2. ed. Porto Alegre: Artmed, 2001.

Recebido em: 17.03.2010

Aprovado em: 10.05.2011

Simone Meyer Sanches é graduada em Psicologia e mestre em Psicologia Escolar pela Pontifícia Universidade Católica de Campinas (PUC-Campinas), doutora em Educação pela Universidade de São Paulo (USP) e docente dos cursos de Psicologia e Educação Física da Universidade Paulista de Campinas. É professora e supervisora do curso de especialização em Psicologia do Esporte do Instituto Sedes Sapientiae, psicóloga do projeto social e equipe de atletismo ORCAMPI/UNIMED (Campinas) e do Clube de Atletismo BM\&FBovespa.

Kátia Rubio é bacharel em Jornalismo pela Faculdade de Comunicação Social Cásper Líbero (1983) e psicóloga pela Pontifícia Universidade Católica de São Paulo (PUC-SP, 1995). Fez mestrado em Educação Física pela Escola de Educação Física e Esporte da USP (EEFE-USP, 1998), doutorado em Educação pela Faculdade de Educação da USP (FE-USP, 2001) e pós-doutorado em Psicologia Social na Universidade Autônoma de Barcelona (2004). Atualmente é professora associada da EEFE-USP, orientadora nos programas de pós-graduação da EEFE-USP e da FE-USP. Coordena o Centro de Estudos Socioculturais do Movimento Humano da EEFE-USP e foi presidente da Associação Brasileira de Psicologia do Esporte nas gestões 2005-2007 e 2007-2009. E-mail: katrubio@usp.br. 